\title{
PROBABILITY OF OCCURRENCE OF HEALTH AND SAFETY RISKS ON SCAFFOLDING CAUSED BY NOISE EXPOSURE
}

\author{
Marek JABŁOŃSKI*, Iwona SZER, Jacek SZER \\ Department of Building Physics and Building Materials, Lodz University of Technology, Lodz, Poland \\ Received 14 June 2018; accepted 06 August 2018
}

\begin{abstract}
The paper presents the results of measurements for one hundred and ten scaffolds located in five cities in different parts of Poland. Measurements were made between April of 2016 and October of 2017. The environmental tests performed on scaffoldings were focused mainly on the sound level. The parameters on which we base our analysis are the value of C-weighted peak sound levels and daily noise exposure level. The noise that affects construction workers on scaffolding may influence the behaviour of workers and increase the risk of accidents. And at the same time, noise exposure laws facilitate identification of high noiseemitting activities and provide effective preventive measures that reduce noise pollution and improve work environments. The analyses carried out confirmed the qualitatively expected dependencies, and allowed us to quantify the impact of noise to which scaffolding workers are exposed. In summary, noise measurements on scaffoldings can be a valuable aid in improving working conditions. The analysis of research results allows understanding hazards related to noise in an accessible way. They provide the opportunity to modify the professional environment so that it is more employee-friendly and does not expose them to problems occurring in a noisy work environment
\end{abstract}

Keywords: environmental studies, noise, noise measurement, noise exposure, scaffolding, construction workers.

\section{Introduction}

Noise is an undesired sound that may be a clear problem in job sectors such as construction. In their workplace, most workers are exposed to noise and its risks. Noise exposure can cause several hazards to safety and health of workers. It is well known that the noise can make it difficult to hear speech and alarm sounds.

The paper presents an analysis of environmental factors (noise) that affect people working on scaffolding. All scaffolds tested were located in large cities (Łódź, Warsaw, Poznan, Wrocław, Lublin), while several of them were located in smaller cities near large agglomerations.

The main use of construction scaffolding is to support construction work at elevated and inaccessible locations. In addition, the scaffolding is also used in other areas, such as the renovation of technological lines, in shipyards, as support structures for advertising, to separate specific areas and form an enclosure, as temporary structures, decorative elements, etc. The often complex design of scaffolding causes the multiplicity of opportunities for occurrence and development of dangerous situations, understood as all unforeseen events which are a threat to people in or around the scaffolding. Employee behaviour and their psy- chophysical state largely depend on structural stability and environmental factors. Environmental factors, i.e. physical stimuli of the external environment, affect both the human being at work and the construction area. These include noise, temperature, humidity, pressure, wind, light, vibration, dust, rainfall, icing, electromagnetic fields, and radiation.

The risk assessment of unfavourable conditions to which the employee may be exposed is an important problem. Current scientific knowledge of the effects that exposure to noise may have on health and safety is not sufficient. The subject literature deals primarily with accidents that occurred on scaffolding (e.g. Błazik-Borowa, Szer 2015; Whitaker et al. 2003; Bellamy 2015), aspects of strength testing of scaffold components, FEM modelling (e.g. Pieńko, Błazik-Borowa 2013) or wind behaviour (e.g. Wang et al. 2014). Various previous studies were focused on noise exposure measurement on construction sites but there is little information on the impact of noise on scaffoldings themselves, which is one of the important environmental factors. Attempts have been made to develop a health damage assessment model to assess the actual

${ }^{*}$ Corresponding author. E-mail: marek.jablonski@p.lodz.pl 
impact of construction noise on health (e.g. Li et al. 2016). As noise is one of the factors that can increase the risk of accidents at work in the construction environment (Smith, Wellens 2017; Fernandez et al. 2009), especially on scaffolding workers, the article focuses on the analyses of noise in the construction sector of Poland. The objectives of this study were to obtain the representative noise exposure levels experienced by on-site workers during typical construction activities, and quantify the noise exposure level of scaffolding workers during typical construction activities.

\section{The impact of noise on people}

The work carried out on a scaffold by a construction worker is counted among particularly dangerous occupations of increased risk. The division of factors affecting occupational safety has been presented in Hoła (2016). One of the harmful factors is the noise that occurs on the scaffolding and its surroundings.

Noise can be severe, disruptive, and can adversely affect human health. The negative effects of noise on the human body are varied, and their size and subsequent consequences depend on many factors. The effects of noise on the human body can be auditory and non-auditory.

Non-auditory effects of noise on the human body are a stress factor leading to disorders of the respiratory system, circulatory system, and other organs. The noise also has a negative effect on the nervous system. In addition, noise reduces speech intelligibility and the perception of warning audio signals. The masking of speech and warning signals not only makes communication difficult, but above all increases the risk of accidents in a noisy environment. Noise is also a problem when we perform activities related to controlling and signaling. To a large extent, it limits the ability to observe and analyze information. It slows down the reaction time and has a negative impact on the decisions made.

Noise sources, typical for construction works that occur on scaffolding or in their vicinity that most often affect employees are grinders, drills, winches, table saws, hammers, concrete mixers, excavators, pneumatic hammers, blowers. The power level of these sources is usually considerable. The impact depends on the distance between the source and the specific employee.

The basic groups of noise sources are:

- machines constituting an energy source, e.g. combustion engines (maximum sound levels A up to 125 $\mathrm{dB}$ ), compressors (up to $113 \mathrm{~dB}$ );

- pneumatic tools and motors, e.g. manual pneumatic tools: hammers, cutters, grinders (up to $134 \mathrm{~dB}$ );

- cutting machines, circular saw blades for metal (up to $115 \mathrm{~dB}$ );

- machining machines, e.g. mechanical hammers (up to $122 \mathrm{~dB}$ );

- metal cutting machine tools, e.g. grinders, drills (up to $104 \mathrm{~dB}$ ).
There are also other noise sources that are unrelated to construction works, but affect the resultant sound level, which has an effect on employees. These are communication noises coming from streets adjacent to the construction site (Jabłoński et al. 2017).

\section{Regulations}

The basic type of noise that is assessed at workplaces is noise in an audible range. The risk assessment resulting from exposure to noise can be made on the basis of registered parameters. The current regulation in the European Union regarding protection of workers is based on the Directive 2003/10/EC (2003) and it should also be included in the Polish regulations on risks related to work (Regulation of the Minister for the Economy and Labour 2005). These documents state a set of minimum disposals with the aim of protecting the workers from the risks for their safety and health, caused or that which may be caused by the noise exposure, with the focus on the hearing risks. They focus on ways to avoid or reduce noise exposure, so that the risks caused by the exposure could be avoided or reduced to the lowest possible level.

In the Directive 2003/10/EC (2003) the physical parameters used as risk predictors are defined as follows:

- daily noise exposure level $\left(L_{E X, 8 h}\right)$ is defined as the time-weighted average of the noise exposure levels for a nominal eight-hour working day. It covers all noises present at work, including impulsive noise;

- C-Weighted peak sound level $\left(L_{\text {Cpeak }}\right)$ is defined as the peak instantaneous $\mathrm{C}$-frequency weighted pressure level recorded during the measurement period.

The exposure limit values and exposure action values in respect of the daily noise exposure levels and peak sound pressure are fixed at:

- exposure limit values: $L_{C p e a k}=140 \mathrm{~dB}$ and $L_{E X, 8 h}=$ $87 \mathrm{~dB}(\mathrm{~A})$, respectively;

- upper exposure action values: $L_{\text {Cpeak }}=137 \mathrm{~dB}$ and $L_{E X, 8 h}=85 \mathrm{~dB}(\mathrm{~A})$, respectively;

- lower exposure action values: $L_{\text {Cpeak }}=135 \mathrm{~dB}$ and $L_{E X, 8 h}=80 \mathrm{~dB}(\mathrm{~A})$, respectively.

In duly justified circumstances, for activities where daily noise exposure varies markedly from one working day to the next, Member States may, for the purposes of applying the exposure limit values and the exposure action values, use the weekly noise exposure level in place of the daily noise exposure level to assess the levels of noise to which workers are exposed, on condition that the weekly noise exposure level as shown by adequate monitoring does not exceed the exposure limit value of $87 \mathrm{~dB}(\mathrm{~A})$.

In Polish regulations, the noise exposure level related to the 8-hour daily worktime $L_{E X, 8 h}$ cannot exceed $85 \mathrm{~dB}$, and the corresponding noise exposure level related to the average weekly worktime cannot exceed $85 \mathrm{~dB}$.

The maximum A-Weighted equivalent sound level $L_{A \text { max }}$, which is the maximum A-Weighted sound pressure level recorded over the period stated, must not exceed $115 \mathrm{~dB}$. 
The C-Weighted peak sound level $L_{\text {Cpeak }}$ must not exceed $135 \mathrm{~dB}$.

\section{Research method}

The measurements and their results described in this paper were a part of the extensive research on façade frame scaffoldings. This research was conducted by five teams consisting of employees from three Universities: Lublin University of Technology, Lodz University of Technology and Wroclaw University of Science and Technology.

As part of the research activities, the following studies were planned (Błazik-Borowa, Szer 2016; Błazik-Borowa et al. 2017; Szer et al. 2017a, 2017b):

- environmental parameters, such as air temperature, relative humidity, atmospheric pressure, illuminance, wind speed, sound level, dustiness;

- technical parameters - deviations from the ideal geometry of the scaffolding (imperfections), technical condition of the elements, forces in the anchoring, forces in the stand of scaffolding frame, frequency of vibrations, wind acting on the scaffolding structure, soil bearing capacity, operational loads;

- life parameters of the workers.

The noise exposure assessment at workplaces consists of the comparison of measured values of noise parameters with their permissible values. The noise limits are defined: for the protection of hearing and for ensuring satisfactory working conditions that do not interfere with the employee's work in the work process.

The noise measurements were not carried out exactly as described in the PN-EN ISO 9612 (2011) standard. Considering characteristics of works performed on scaffolds, the study was conducted accordingly to individually adjusted research program that deviates from the usual measurement standards relating to the noise measurements at workplaces. The tests were carried out for the same work periods during which the employees performed standard activities on the scaffolding. The tests were not focused on identifying workstations or creating groups with homogeneous exposure to noise. The scaffold was treated as a workstation and the level of noise exposure was determined. The exact measurement plan is presented below.

Sound level tests were conducted in the middle of the span. The measurements were carried out in six, nine or twelve places on the scaffolding (the number depends on the size of the scaffolding).

Measurements were taken in the extreme fields and in the fields spaced evenly on the scaffold, using the following scheme:

- 3 or 4 measurements at the first full level (work platform);

- 3 or 4 measurements at half height (work platform);

- 3 or 4 measurements at the highest level (work platform).

Additional information has been registered at each measuring point. This information are composed by in

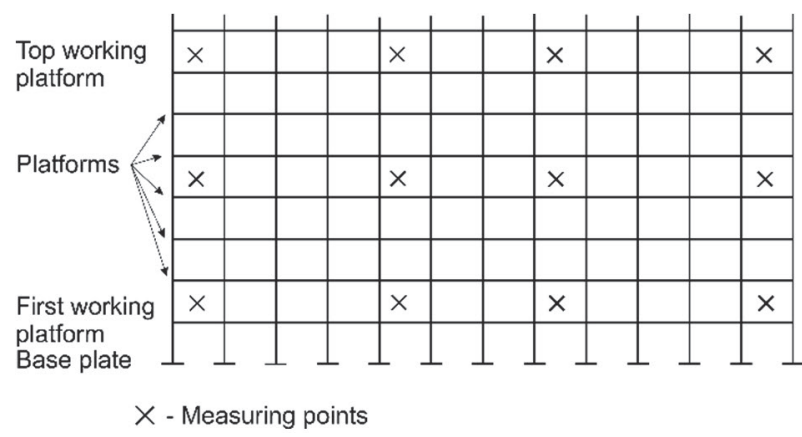

Figure 1. Exemplary arrangement of measurement points

which the photograph of the most noisy process when measuring at a specific point, a brief description of the source and the distance from the measuring point. An exemplary arrangement of measuring points is shown in Figure 1.

The measurement time was scheduled according to the working periods of workers at most construction sites in Poland, namely, from 07.00 AM to 4.00 PM. Measurements were made at 3-hour intervals, i.e. the first round of tests from 8.00 AM, second round of research from 11.00 AM, third round of research from 2.00 PM. The aim of recording data at various times of the day was to obtain information on how the level of noise during the day changes. Measurements were carried out for five consecutive days of the week. As a result, a fairly complete view of the noise impact on workers' performance on the scaffolding was obtained.

\subsection{Measuring equipment}

The sound level meter DB200 was used to measure the sound level. Two parameters were simultaneously recorded at each measuring point for approximately 6 minutes: C-Weighted peak sound level $-L_{\text {Cpeak }}$ and A-Weighted equivalent sound level $-L_{A e q}$.

The results of the recorded acoustic parameters from all noise sources for the selected day, selected hour and selected one measuring point are shown in Figure 2.

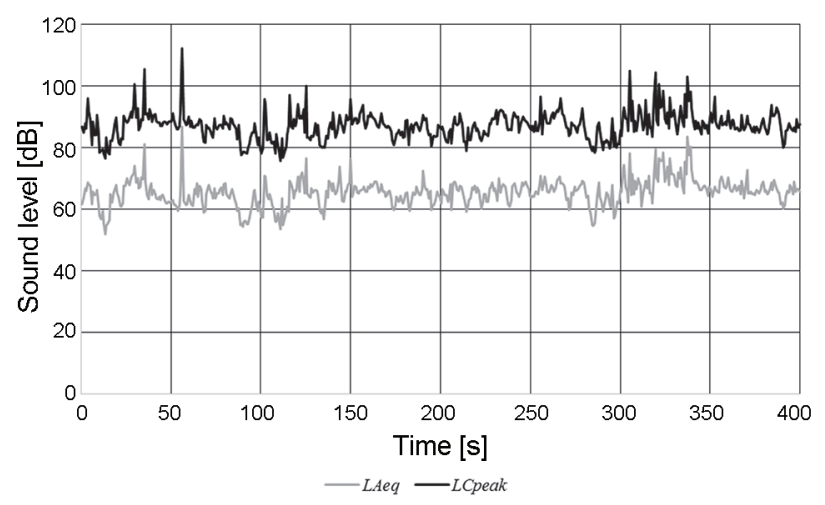

Figure 2. C-Weighted peak sound level $L_{\text {Cpeak }}$ (upper course) and A-Weighted equivalent sound level $L_{\text {Aeq }}$ (lower course) registered at one measuring point 
As construction noise is generally differentiated and intermittent, it is reasonable to use the continuous steadystate indicator $L_{A e q, T}$, which is calculated by taking an average of the fluctuant noise level during a period of time (Eqn (1)):

$$
L_{A e q, T m}=10 \log \left[\frac{1}{N} \sum_{i=1}^{N} 10^{0,1 L_{A e q, T m i}}\right],
$$

where: $L_{A e q, T m}$ - the A-Weighted equivalent continuous sound pressure level for task $m$; $N$ - the total number of task samples.

Noise exposure level $L_{E X, 8 h}$ is calculated by normalizing $L_{A e q, T}$ to the length of a typical working day, according to the calculation procedures proposed in PN-EN ISO 9612 (2011) (Eqns (2) and (3)). In this analysis, for each measurement point, in each round from the recorded data C-Weighted peak sound level $L_{\text {Cpeak }}$ was determined and A-weighted equivalent sound level $L_{A e q, T}$ were calculated from witch $L_{E X, 8 h}$ was calculated:

$$
\begin{aligned}
& L_{E X, 8 h, m}=L_{A e q, T m}+10 \log \left(\frac{T_{m}}{T_{0}}\right) ; \\
& L_{E X, 8 h}=10 \log \left[\sum_{m=1}^{M} 10^{0,1 L_{E X, 8 h, m}}\right],
\end{aligned}
$$

where: $m$ - the divided task $m ; T_{m}$ - the duration of task $m ; T_{0}$ - the reference duration, $T_{0}=8 \mathrm{~h} ; L_{A e q, T m}-$ the A-Weighted equivalent continuous sound pressure level for task $m ; L_{E X, 8 h, m}$ - the noise contribution from task $m$ to daily noise exposure level.

\section{Results and discussion}

The basic element of all statistical analyses of a finite cardinality is the determination of the variable distribution observed in this cardinality, i.e. the assignment of values assumed by a given variable of their respective frequency occurrence. The distribution of the analyzed variable can be represented by a histogram. The histogram is used to visually assess the nature of the variable distribution. In the frequency distribution graph, for example, you can see which value occurs most frequently, whether most of the observed values are close to the average, etc. Such charts were created for 22 tested scaffolds in individual cities.

Since the change in the sound level by $1 \mathrm{~dB}$ is imperceptible, and only the change by $3 \mathrm{~dB}$ is palpable, the measurement range of sound levels is divided into $3 \mathrm{~dB}$ subranges, in which the occurrence frequency of a given sound level was calculated.

The values of the equivalent sound level $L_{A e q, T}$ recorded on selected scaffolds at $8 \mathrm{AM}, 11 \mathrm{AM}$ and $14 \mathrm{AM}$ are shown in Figure 3. These graphs reveal significant differences in $L_{A e q, T}$ values depending on the time of measurements. You can see that after 2 PM (Figure 3(c)) the number of events with higher $L_{A e q, T}$ values decreases compared to the values obtained from measurements performed at $8 \mathrm{AM}$ and $11 \mathrm{AM}$. This may be due to the fact that high-
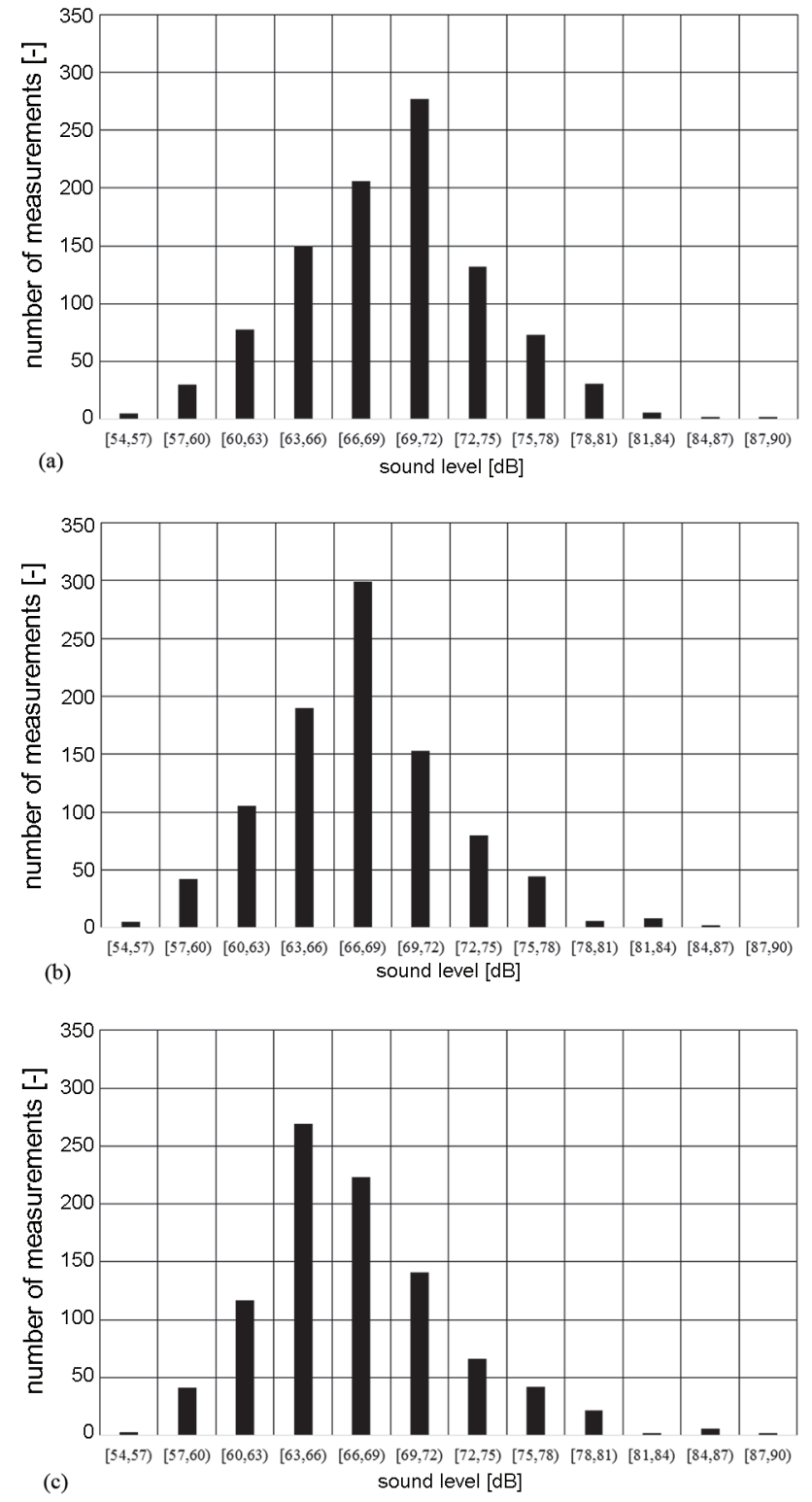

Figure 3. The values of the equivalent sound level $L_{\text {Aeq, } T}$ recorded on scaffolds for one selected city at: (a) - $8 \mathrm{AM}$;

(b) - 11 AM; (c) - 2 PM

er intensity of work on scaffolding is performed in early morning hours and before noon.

The diagram (Figure 4) shows the distribution of peak C-Weighted level for five selected areas. It shows the peak level distribution for all scaffolds on which the tests were carried out.

The occurrence frequency of excessive sound level values on scaffolds was also analyzed. Table 1 illustrates the probability of a dangerous situation occurrence having impact on an employee's health due to exposure to noise. The values were defined as the ratio of the number of measurements for which peak sound level exceeding $135 \mathrm{~dB}$ was observed to the number of all measurements on analyzed scaffoldings.

The summarized results of measurements are included in Table 2, in which the highest values of measured 
Table 1 . The probability of a dangerous situation occurrence having impact on an employee's health

\begin{tabular}{|l|c|c|c|}
\hline Location & $\begin{array}{c}\text { The number of exceeded } L_{\text {Cpeak }} \\
\text { values }=135 \mathrm{~dB}\end{array}$ & $\begin{array}{c}\text { The number of all } \\
\text { measurements }\end{array}$ & $\begin{array}{c}\text { The probability of exposure to } \\
\text { excessive noise }\end{array}$ \\
\hline Łódź & 0 & 2827 & 0 \\
\hline Lublin & 3 & 2280 & 0.0013 \\
\hline Poznań & 0 & 2258 & 0 \\
\hline Warsaw & 6 & 2335 & 0.0026 \\
\hline Wrocław & 1 & 2532 & 0.0004 \\
\hline
\end{tabular}
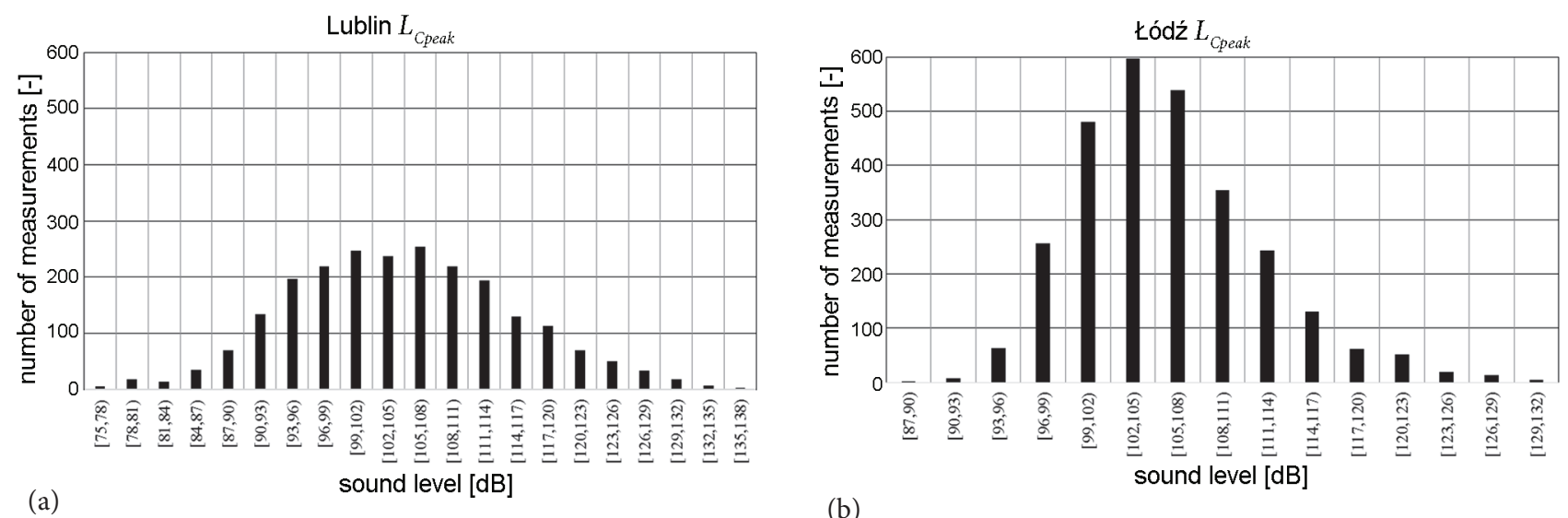

(b)
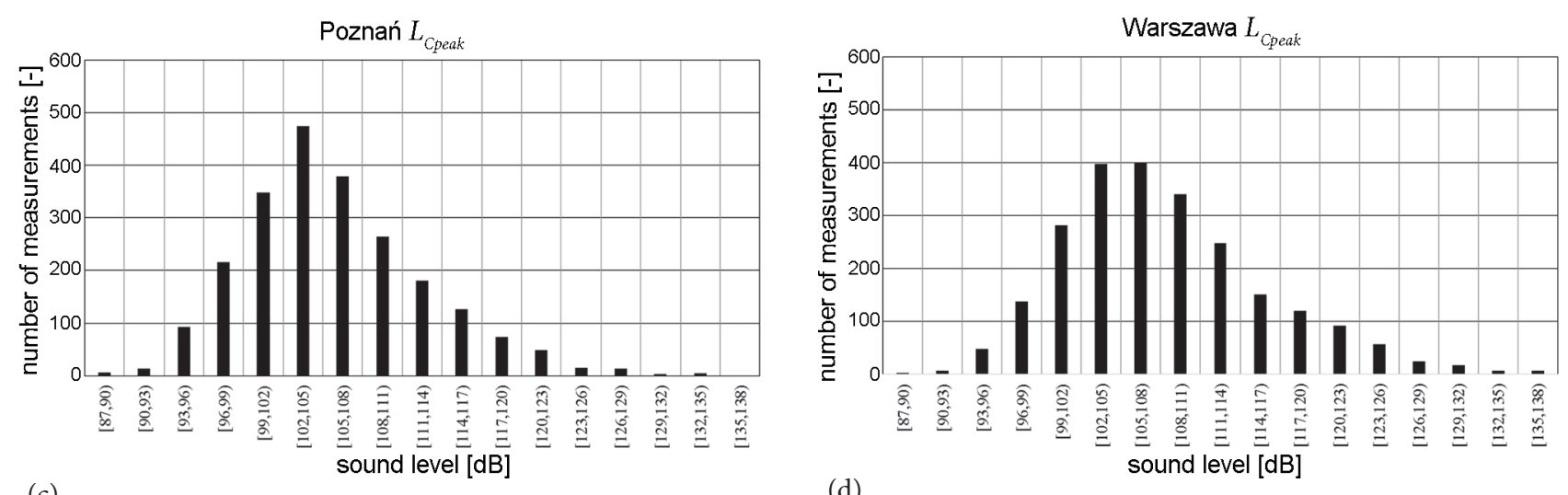

(d)

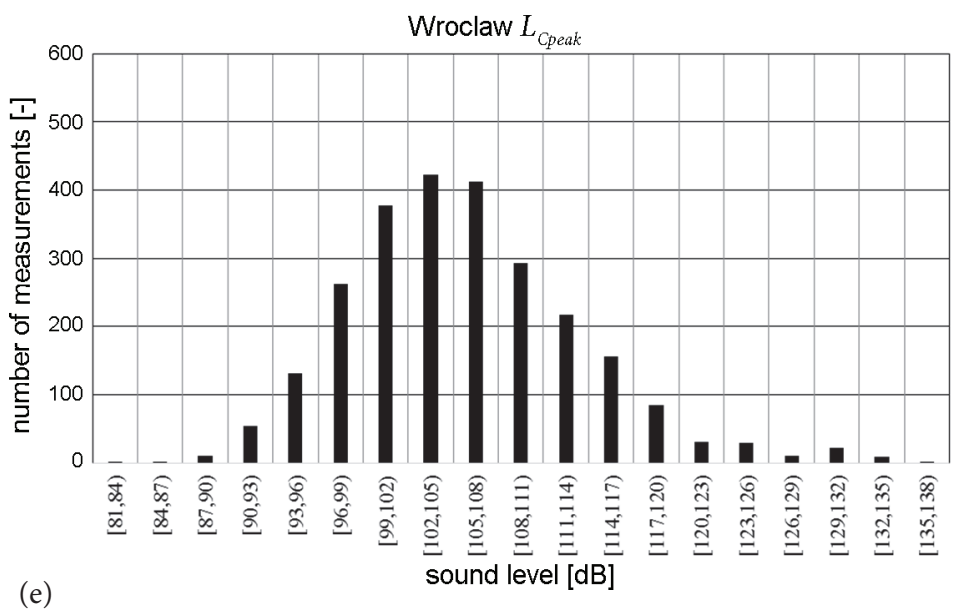

Figure 4. C-Weighted peak sound level registered on scaffolds: (a) - in Lublin;

(b) - in Łódź; (c) - in Poznań; (d) - in Warsaw; (e) - in Wrocław 
Table 2. The highest recorded values of the measured parameters

\begin{tabular}{|l|c|c|c|c|}
\hline Location & $\begin{array}{c}L_{\text {Aeq, } T} \\
(\mathrm{dBA})\end{array}$ & $\begin{array}{c}L_{\text {Amax }} \\
(\mathrm{dBA})\end{array}$ & $\begin{array}{c}L_{\text {Cpeak }} \\
(\mathrm{dBC})\end{array}$ & $\begin{array}{c}L_{E X, 8 h} \\
(\mathrm{~dB})\end{array}$ \\
\hline Łódź & 90.7 & 104.1 & 132.0 & 73.4 \\
\hline Lublin & 108.8 & 124.9 & 135.2 & 83.5 \\
\hline Poznań & 90.2 & 106.8 & 134.2 & 75.9 \\
\hline Warsaw & 90.7 & 106.9 & 135.4 & 78.2 \\
\hline Wrocław & 90.5 & 105.1 & 135.2 & 76.5 \\
\hline
\end{tabular}

parameters for all scaffoldings located in each of the assessed cities were given. The table shows the highest equivalent A-Weighted level, the highest peak C-Weighted level, the highest maximum A-Weighted equivalent sound level and the highest noise exposure level related to the 8-hour daily worktime.

Major factors that influence occupational noise exposure levels experienced by workers can provide references for controlling noise emissions in order to improve work environments. Daily work time and work intensity should be strictly controlled in order to shorten the exposure duration and reduce the exposure level, respectively.

In general the data presented in Table 1 and 2 provides a conclusion that the sound environment typical for scaffolding workers is considerably noisy and potentially detrimental to health, as there are cases when the upper limit is exceeded.

Table 1 presents the probability of a dangerous situation affecting the health of the employee. Despite the fact that it is not high, it shows that during particularly noisy works on the scaffolding, employees may be exposed to excessive noise.

Table 2 presents the highest recorded values of the measured parameters. The values of maximal sound level and peak sound level are exceeded repeatedly.

Graphs in Figure 3 show the values of the equivalent sound level $L_{\text {Aeq,T }}$ registered on selected scaffolds at $8 \mathrm{AM}$, $11 \mathrm{AM}$ and 2 PM. The values of $L_{\text {Aeq, } T}$, differ quite significantly, depending on the time of measurements, as on many scaffolds higher intensity of work occurs in the morning and before noon. At $8 \mathrm{AM}$ events with sound lev-

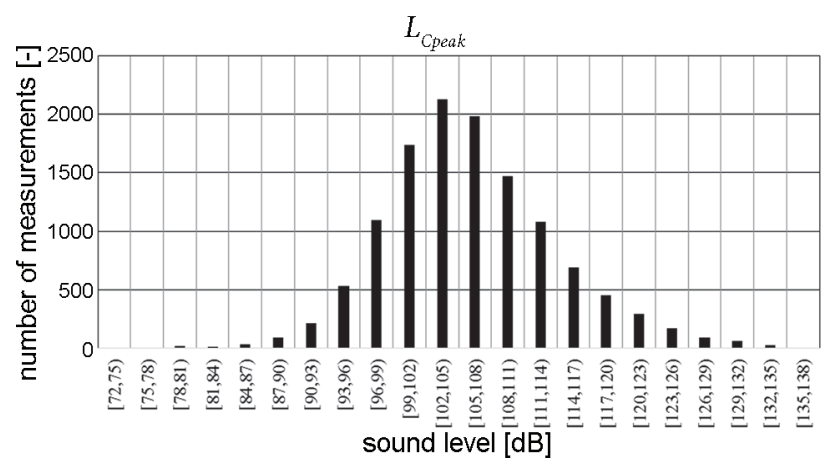

Figure 5. C-weighted peak sound level registered for all scaffolds els in the 69-72 dB range were recorded most often (Figure 3(a)) and at $11 \mathrm{AM}$ the recorded values were in the 66-69 dB range (Figure 3(b)). After 2 PM (Figure 3(c)) the number of events with higher $L_{\text {Aeq, } T}$ values decreases compared to the values obtained from measurements made at $8 \mathrm{AM}$ and $11 \mathrm{AM}$. From the graph in Figure 3(c), it can be read that work performed after $2 \mathrm{PM}$ most often generates sound levels in the range of 63-66 dB.

On the basis of the presented graphs it can be stated that the distribution of the peak sound level on scaffolding in different cities has its own distinct features. It depends on the type of work carried out and the equipment used. The general list and Figure 5 shows that C-Weighted peak sound level usually reached values between $102 \mathrm{~dB}$ and $108 \mathrm{~dB}$, but it exceeded $135 \mathrm{~dB}$ repeatedly, which can be considered dangerous. This situation occurred at 10 scaffoldings out of 110 tested. Such situations should be considered harmful to health, and a high-risk, due to the protection of hearing.

The exposure level referred to an eight-hour workday usually took values from $62 \mathrm{~dB}$ to $65 \mathrm{~dB}$. The highest calculated values exceeded the permissible value of $80 \mathrm{~dB}$, which can be considered dangerous.

\section{Conclusions}

The aim of the study was to analyze the noise levels that the construction workers are exposed to. Field measurements provide practical environmental data for typical construction activities.

The noise measurements were not carried out exactly as the standards indicate. The research was carried out when the employees performed standard activities on the scaffolding. Workstations were not identified and groups with homogeneous exposure to noise were not created, but the scaffold was treated as one workstation where the noise parameters were determined.

The main conclusion that can be drawn is that there are high levels of noise in any work environment related to construction. The vast majority of people working on a construction site are affected by excessively high level of noise exposure within a whole working day. When the noisiest tools are used, the peak sound level and the exposure level of the sound are exceeded.

Regarding the intensity of sound exposure, the building sector can be divided into three distinct groups. The first one concerns construction sites, where machines are used constantly, which indicates particularly high level of noise exposure. In case of the second group building machines are used occasionally, which generates the average sound exposure level. Finally, the third group is related to building sites, where conducted actions do not require application of any electrical devices, which is why there is not any noise exposure.

Although the likelihood of a dangerous situation that could affect the health of an employee is low, any exceedance of the limit value causes irreparable damage to hearing and can lead to the impairment or the loss of hearing. 
As the noise on the scaffolding varies greatly depending on the time of the day, construction work should be planned in a way that minimizes the risk of exposure to noise. This can be achieved by planning work processes properly.

The level of exposure to noise can be reduced more effectively by incorporating preventive measures into the design of workstations and workplaces, as well as by selecting work equipment, procedures and methods, as to reduce the risks at the source.

In order to reduce sound exposure the hearing protection devices should be used in the workplace. However, this guidance is usually ignored by employees due to the ignorance of the serious danger

The insufficient awareness of severe effects caused by excessive noise exposure amongst workers as well as employers is a common problem. The majority view is that constant exposure to noise at the building site can only affect a hearing system but actually this factor induces many more adverse consequences.

Employers should make adjustments according to technical progress and scientific knowledge regarding risks related to noise exposure, with the aim of improving the health and safety protection of workers.

It is possible to control the noise exposure level by affecting a source of sound, an environment or a receiver. However, the reduction of noise generated by working machines is difficult to achieve. The easiest and the most effective way of sound exposure adjustment consists in employee (receiver), who has to be equipped with hearing protection devices, which should be chosen appropriately to specific conditions of considered building site.

\section{Acknowledgement}

This work was supported by the National Centre for Research and Development within Applied Research Programme (agreement No. PBS3/A2/19/2015 "Modelling of Risk Assessment of Construction Disasters, Accidents and Dangerous Incidents at Workplaces Using Scaffoldings").

\section{References}

Bellamy, L. J. 2015. Exploring the relationship between major hazard, fatal and non-fatal accidents through outcomes and causes, Safety Science 71: 93-103. https://doi.org/10.1016/j.ssci.2014.02.009

Błazik-Borowa, E.; Szer, J. 2015. The analysis of the stages of scaffolding "life" with regard to the decrease in the hazard at building works, Archives of Civil and Mechanical Engineering 15: 516-524. https://doi.org/10.1016/j.acme.2014.09.009

Błazik-Borowa, E.; Szer, J. 2016. Basic elements of the risk assessment model for the occurrence of dangerous events on scaffoldings, Przeglad Budowlany 10: 24-29 (in Polish).

Błazik-Borowa, E.; Bęc, J.; Robak, A.; Szulej, J.; Wielgos, P.; Szer, I. 2017. Technical factors affecting safety on a scaffolding, in E. Fidelis, M. Behm (Eds.). Towards better safety, health, wellbeing, and life in construction. Bloemfointein: Department of Built Environment, Central University of Technology, 154-163.
Directive 2003/10/EC of the European Parliament and of the Council of 6 February 2003 on the minimum health and safety requirements regarding the exposure of workers to the risks arising from physical agents (noise). DOUE, 2003.

Fernandez, M. D.; Quintana, S.; Ballesteros, J. A.; Chavarria, N. 2009. Noise exposure of workers of the construction sector, Applied Acoustics 70(5): 753-760. https://doi.org/10.1016/j.apacoust.2008.07.014

Hoła, B. 2016. Work safety in the construction processes. Wrocław: Oficyna Wydawnicza Politechniki Wrocławskiej (in Polish).

Jabłoński, M.; Szer, I.; Szer, J.; Błazik-Borowa, E. 2017. Acoustic climate on scaffolding, Materiaty Budowlane 8: 32-34.

Li, X.; Song, Z.; Wang, T.; Zheng, Y.; Ning, X. 2016. Health impacts of construction noise on workers: A quantitative assessment model based on exposure measurement, Journal of Cleaner Production 135: 721-731. https://doi.org/10.1016/j.jclepro.2016.06.100

Pieńko, M.; Błazik-Borowa, E. 2013. Numerical analysis of loadbearing capacity of modular scaffolding nodes, Engineering Structures 48: 1-9. https://doi.org/10.1016/j.engstruct.2012.08.028

PN-EN ISO 9612 Akustyka - Wyznaczanie zawodowej ekspozycji na hałas - Metoda techniczna. Polish standard, 2011 (in Polish).

Regulation of the Minister for the Economy and Labour „Rozporządzenie Ministra Gospodarki i Pracy z dnia 5 sierpnia 2005 r. w sprawie bezpieczeństwa i higieny pracy przy pracach związanych z narażeniem na hałas lub drgania mechaniczne" (Dz.U. z 2005 r., Nr 157, poz. 1318) (in Polish).

Smith, A.; Wellens, B. 2017. Noise and occupational health and safety, in The first European Forum on Efficient Solutions for Managing Occupational Noise Risks. Noise at Work, 2017, Paris, France.

Szer, I.; Błazik-Borowa, E.; Szer, J. 2017a. The influence of environmental factors on employee comfort based on an example of location temperature, Archives of Civil Engineering 63: 193-174. https://doi.org/10.1515/ace-2017-0035

Szer, I.; Szer, J.; Cyniak, P.; Błazik-Borowa, E. 2017b. Influence of temperature and surroundings humidity on scaffolding work comfort, in A. Bernatik, L. Kocurkova, K. Jørgensen (Eds.). Prevention of accidents at work. Taylor \& Francis Group, 19-23. https://doi.org/10.1201/9781315177571-5

Wang, F.; Tamura, Y.; Yoshida, A. 2014. Interference effects of a neighbouring building on wind loads on scaffolding, Journal of Wind Engineering and Industrial Aerodynamics 125: 1-12. https://doi.org/10.1016/j.jweia.2013.11.009

Whitaker, S. M.; Graves, R. J.; James, M.; McCann, P. 2003. Safety with access scaffolds: development of a prototype decision aid based on accident analysis, Journal of Safety Research 34: 249-261. https://doi.org/10.1016/S0022-4375(03)00025-2 